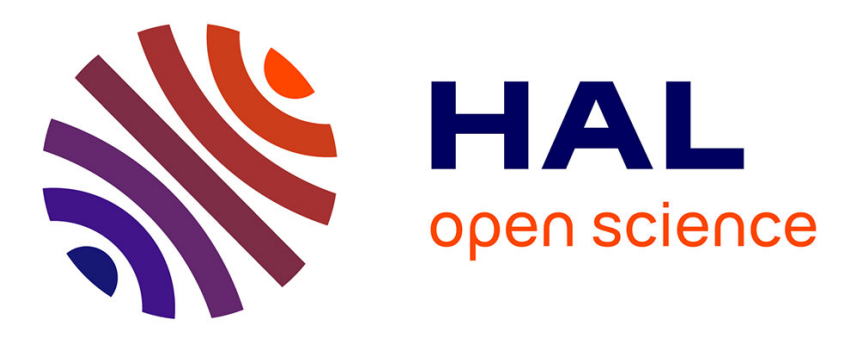

\title{
Influence of body segments' parameters estimation models on inverse dynamics solutions during gait
}

Guillaume Rao, David Amarantini, Eric Berton, Daniel Favier

\section{To cite this version:}

Guillaume Rao, David Amarantini, Eric Berton, Daniel Favier. Influence of body segments' parameters estimation models on inverse dynamics solutions during gait. Journal of Biomechanics, 2006, 39 (8), pp.1531-1536. 10.1016/j.jbiomech.2005.04.014 . hal-01442068

\section{HAL Id: hal-01442068 \\ https://hal.science/hal-01442068}

Submitted on 15 Nov 2017

HAL is a multi-disciplinary open access archive for the deposit and dissemination of scientific research documents, whether they are published or not. The documents may come from teaching and research institutions in France or abroad, or from public or private research centers.
L'archive ouverte pluridisciplinaire HAL, est destinée au dépôt et à la diffusion de documents scientifiques de niveau recherche, publiés ou non, émanant des établissements d'enseignement et de recherche français ou étrangers, des laboratoires publics ou privés. 


\title{
Influence of body segments' parameters estimation models on inverse dynamics solutions during gait
}

\author{
Guillaume Rao*, David Amarantini, Eric Berton, Daniel Favier \\ Aerodynamics and Biomechanics of Motion Laboratory, LABM-USR 2164-CNRS/Université de la Méditerranée, \\ Parc Scientifique et Technologique de Luminy, 163, Avenue de Luminy-Case postale 918, 13288 Marseille cedex 9, France
}

Accepted 13 April 2005

\begin{abstract}
The purpose of the present study was to examine the influence of anthropometric data on joint kinetics during gait. We particularly focused on the sensitivity of inverse dynamics solutions to the use of models for body segment parameters (BSP) estimation. Six often used estimation models were selected to provide BSP values for the three segments of the lower limb. Kinematics and dynamics were sampled from seven subjects performing barefoot gait at three different speeds. Joint kinetics were estimated with the bottom-up method using BSP values derived from each estimation model as anthropometric inputs. The BSP estimates were highly sensitive to the model used with deviations ranging from at least $9.73 \%$ up to $60 \%$. Maximal variations of peak values for the hip joint flexion/extension moment during the swing phase were $20.11 \%$. Hence, our findings suggest that the influence of BSP cannot be neglected. Observed deviations are especially due to the effect of varying simultaneously the mass, moments of inertia and the center of mass location values, according to the underlying relationship of interdependency linking each component. Considering both the differences found in joint kinetics and the level of accuracy of BSP models, evidence is provided that using multiple regression BSP estimation functions derived from Zatsiorsky and Seluyanov (Biomechanics VIII-B, 1983, pp. 1152-1159) should be recommended to assess joint kinetics.
\end{abstract}

(C) 2005 Elsevier Ltd. All rights reserved.

Keywords: Joint kinetics; BSP estimation models; Inverse dynamics; Gait

\section{Introduction}

The estimation of net joint forces and torques deals with solving the problem of inverse dynamics (Hatze, 2000; Winter, 1990), where body segments parameters (body segment parameters (BSP): masses, center of mass locations, moments of inertia) and kinematics are given as inputs to the equations of motion, with or without dynamic data depending on the method used (Cahouet et al., 2002; Winter, 1990).

The sensitivity of joint kinetics to the accuracy of kinematic and dynamic data is clearly understood. It is

\footnotetext{
*Corresponding author. Tel.: + 33491266178 ; fax: +33491411691

E-mail address: rao@labm.univ-mrs.fr (G. Rao).
}

typically due to inaccuracies in the coordinates of anatomical landmarks (see, e.g., Holden and Stanhope, 1998) and/or the approximation of accelerations (Challis and Kerwin, 1996) as well as forceplate uncertainties (Silva and Ambrosio, 2004), but can be reduced using appropriate signal processing techniques (Cahouët et al., 2002; Charlton et al., 2004; Giakas and Baltzopoulos, 1997; McCaw and DeVita, 1995; Van den Bogert and de Koning, 1996). On the contrary, the influence of BSP values is more controversial, especially during gait. Pearsall and Costigan (1999), Challis and Kerwin (1996) and Ganley and Powers (2004) reported low importance of BSP uncertainties, while others conversely demonstrated that misestimating BSP can generate significant variations of joint kinetics estimates (Andrews and Mish, 1996; Kingma et al., 1996; Silva and Ambrosio, 
2004). This issue remains debated because the effects of BSP estimates on joint kinetics cannot be simply quantified, although they are conveniently obtained from BSP estimation models. Indeed, multiple linear regressions and partial derivatives computation (Challis and Kerwin, 1996) are unsuitable to quantify the relative influence of individual BSP components without assuming their independence. However, the BSP estimates for a given segment can all be computed from its volume, density and mass distribution (Shan and Bohn, 2003), introducing interdependence between all the BSP values. Although attractive, the numerical approach depicted in Pearsall and Costigan (1999) also has the drawback of neglecting the underlying relationship between the BSP components.

The present study undertook to highlight the sensitivity of inverse dynamics solutions to different sets of anthropometric data. Resorting to the use of six BSP estimation models, inverse dynamics computations were carried out to estimate the three-dimensional net forces and torques at the ankle, knee and hip joints during gait performed at three different speeds.

\section{Methods}

\subsection{Subjects}

Seven subjects (three males and four females; age: $27.0 \pm 4.5$ years; mass: $63.6 \pm 10.5 \mathrm{~kg}$; height: $1.68 \pm 0.09 \mathrm{~m}$, means $\pm \mathrm{SD}$ ) students at the Sport Sciences Faculty of Marseille gave informed consent to participate in the study.

\subsection{Instrumentation}

The three-dimensional kinematics of 15 markers placed on the subject's lower limbs (Helen Hayes Hospital markers set) were recorded at $120 \mathrm{~Hz}$ using a six cameras Vicon 624 motion analysis system (Vicon Motion System, Lake Forest, CA). The local reference frames were originated at the distal end of each segment, with $\vec{x}, \vec{y}$, and $\vec{z}$ representing, respectively, the anteroposterior, transverse and longitudinal axes. Synchronously with the kinematics, ground reaction data were recorded at $600 \mathrm{~Hz}$ from a six component forceplate (AMTI, Model LG6-4-CE, Watertown, USA) invisibly fixed into the floor $4 \mathrm{~m}$ from the beginning of a $7 \mathrm{~m}$ long walkway.

\subsection{Instructions}

Subjects were asked to walk barefoot along the walkway with right foot forceplate contact at three different walking cadences: (i) preferred $(112.98 \pm 14.05$ steps per minute); (ii) low $(76.83 \pm 18.82$ steps per minute); and (iii) fast ( $140.12 \pm 28.78$ steps per minute). The subjects were given about five training trials at each cadence before the recording session.

\subsection{BSP estimation}

The segment masses, moments of inertia and center of mass locations were estimated using six often used BSP estimation models: one geometric model (Hanavan, 1964), two models derived from cadavers' studies (Dempster, 1955; Chandler et al., 1975) and three in vivo mass-scanning models based on living subjects (Zatsiorsky and Seluyanov, 1983 (Z2); Zatsiorsky et al., 1990 (Z1); De Leva, 1996). For each model, all anthropometric data necessary as inputs were measured by following the authors' recommendations. The moments of inertia were computed about the rotation axis using the parallel axis theorem according to the reference frame convention. To use Dempster's model in three-dimensional analysis, the moments of inertia around the transverse and antero-posterior axes were set equal based upon Hanavan (1964), and the longitudinal moment of inertia was set to 0 .

\subsection{Data processing}

The three-dimensional net forces and moments at the right ankle, knee and hip joints were estimated by solving the dynamical equations of a free body diagram of the lower limb with four rigid segments (feet, shank, thigh and pelvis). Inverse dynamics computations were carried out using Vicon BodyBuilder software (Vicon Motion System, Lake Forest, CA) by using BSP derived from each selected estimation model as anthropometric inputs. For comparisons, the results were normalized by subjects' body mass, while time was expressed as percentage of total gait cycle duration. As Ganley and Powers (2004), our investigations focused on the flexion/ extension moments, given that oscillations in kinematic profiles typically occur around the transverse axis (Besier et al., 2003) and that the effect of varying BSP was about similar on force and moment (Pearsall and Costigan, 1999).

\subsection{Statistics}

For statistical purposes, one-way ANOVAs (Models effect) were applied to the mean values over the seven subjects of (i) each BSP component derived from the six estimation models (ii) the maximum absolute value reached during each phase by the flexion/extension moments about the ankle, knee and hip joints and (iii) the normalized RMS values (NRMS; Cahouët et al., 2002) computed separately for stance and swing 
phases with

$$
\begin{gathered}
\mathrm{NRMS}_{j}=\frac{\sqrt{(1 / T) \int_{0}^{T} s_{j}(t)^{2} \mathrm{~d} t}}{(1 / n) \sum_{i=1}^{n}\left(\operatorname{Max}_{0<t<T}\left(s_{i}(t)\right)-\operatorname{Min}_{0<t<T}\left(s_{i}(t)\right)\right)}, \\
j=\{1, \ldots, 6\}, n=6,
\end{gathered}
$$

where $\mathrm{NRMS}_{j}$ is the value of the normalized RMS for the flexion/extension moment $s_{j}(t)$ estimated for each subject using BSP estimation model $j$ at time $t . j$ numbered $1-6$ refers to models. $T$ is the total duration of gait cycle.

An alpha level of 0.05 was set for all statistical tests to offer a good compromise between type I and type II errors with high enough stringency.

\section{Results}

\subsection{BSP components}

The results show that the BSP values substantially differ as a function of the BSP model used (see Fig. 1 for

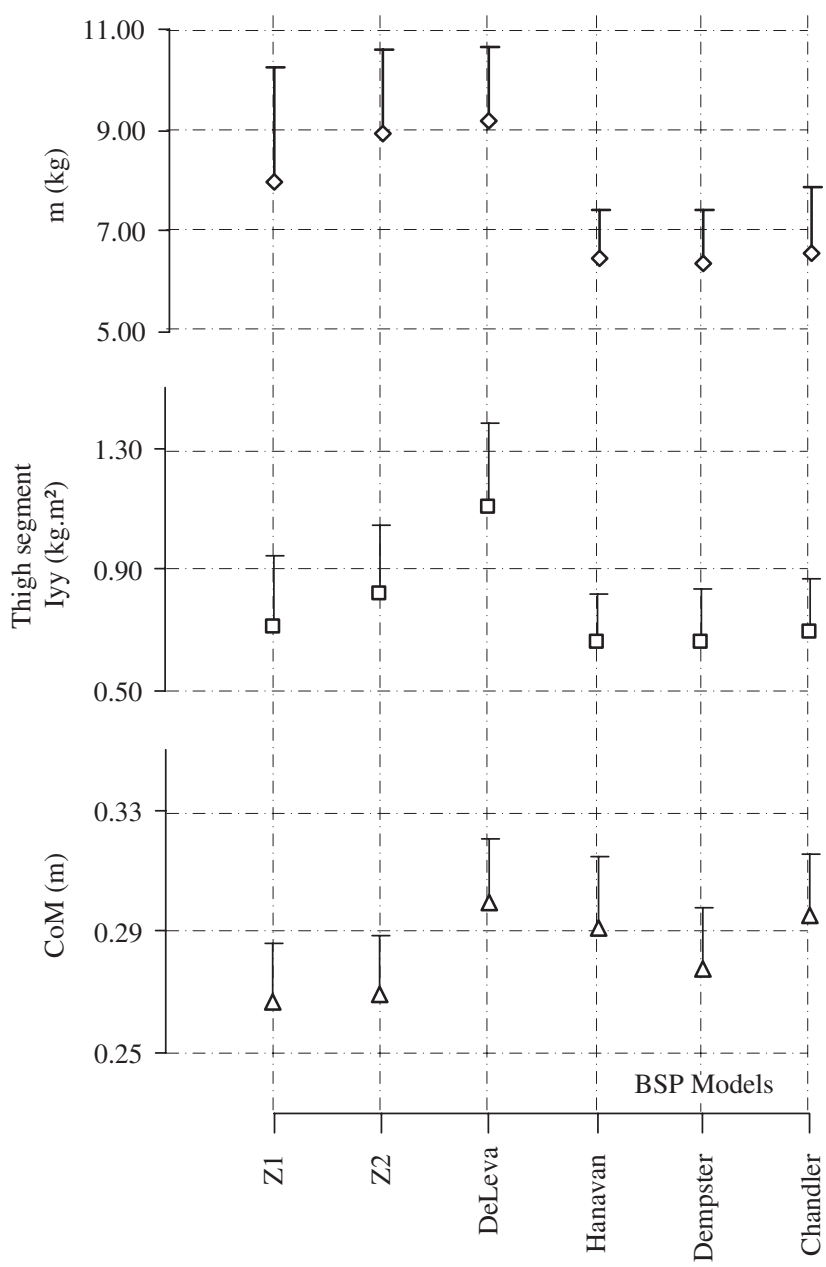

Fig. 1. Means $( \pm \mathrm{SD})(n=7)$ of BSP components estimated at the thigh using the six selected estimation models. $m$ is the mass, Iyy the transverse moment of inertia and CoM the center of mass location calculated with respect to the distal joint.
Table 1

Means $( \pm \mathrm{SD})$ of inertial properties (mass: $m$, transverse moment of inertia: Iyy, center of mass location: CoM) estimated for the foot, shank and thigh segments using six different BSP estimation models

\begin{tabular}{llll}
\hline & Foot & Shank & Thigh \\
\hline $\mathrm{m}(\mathrm{kg})$ & $0.85 \pm 0.11$ & $2.89 \pm 0.19$ & $7.59 \pm 1.30$ \\
& 37.95 & 15.72 & 37.61 \\
Iyy $\left(\mathrm{kg} \mathrm{m}^{2}\right)$ & $0.02 \pm 5.74 \times 10^{-3}$ & $0.21 \pm 0.02$ & $0.78 \pm 0.17$ \\
& 61.51 & 21.98 & 58.40 \\
CoM $(\mathrm{m})$ & $0.13 \pm 0.02$ & $0.24 \pm 0.01$ & $0.28 \pm 0.01$ \\
& 29.05 & 9.73 & 11.29 \\
\hline
\end{tabular}

Statistical analyses reveal significant main Models effects $(p<0.05)$ concerning all the components for all the segments. For each BSP component, the value in italic is its corresponding mean percentage of variation over the BSP estimation models, computed by dividing its range of variation by its mean value $(\times 100)$.

the thigh). The ANOVAs reveal significant main Models effects for all the BSP with variations ranging from at least $9.73 \%$ up to $60 \%$ (Table 1). The largest differences in BSP are for the foot, where the mean of BSP variations is $42.84 \pm 16.77 \%$.

Moreover, the post hoc comparisons show that the effect of Models operates differently for each individual BSP component. Especially, the mass of the foot $\left(m_{\mathrm{F}}\right)$ is the only BSP value that differs between all six models $\left(F_{5,30}=79.97 ; p<0.05\right)$, with mean values ranging from 0.65 to $0.98 \mathrm{~kg}$. From a more general viewpoint, the results indicate that $\mathrm{BSP}$ estimates from living-based models are significantly different than those from all other models. This is especially observed for the thigh mass $\left(m_{\mathrm{T}}\right)$, which estimates from Z1, Z2 and DeLeva are significantly higher than those from all other models $\left(8.71 \pm 0.64\right.$ vs. $\left.6.46 \pm 0.10 \mathrm{~kg} ; F_{5,30}=15.04, p<0.05\right)$. However, the analysis of the thigh moment of inertia $\left(\mathrm{Iyy}_{\mathrm{T}}\right)$ reveals that the BSP values from DeLeva can exceed all the other estimates $\left(F_{5,30}=24.35 ; p<0.05\right)$, while $\mathrm{Z} 2$ provides intermediate values only similar to that obtained using Chandler.

\subsection{Joint kinetics (flexion/extension moments)}

The influence of varying BSP on joint kinetics is depicted in Fig. 2; NRMS and peak variations are presented in Table 2. Note that, in the following sections, the term " $j$ outputs" refers to the flexion/ extension moment computed with BSP data from model $j$ as anthropometric inputs.

At the ankle joint, main Models effects are shown during stance, on NRMS values for preferred and fast cadences as well as on peaks values for low and fast cadences. Although significant, these results must be carefully considered because their amplitude of variation is only $0.80 \%$ maximum, for NRMS at fast cadence $\left(F_{5,30}=6.79 ; p<0.05\right)$. 


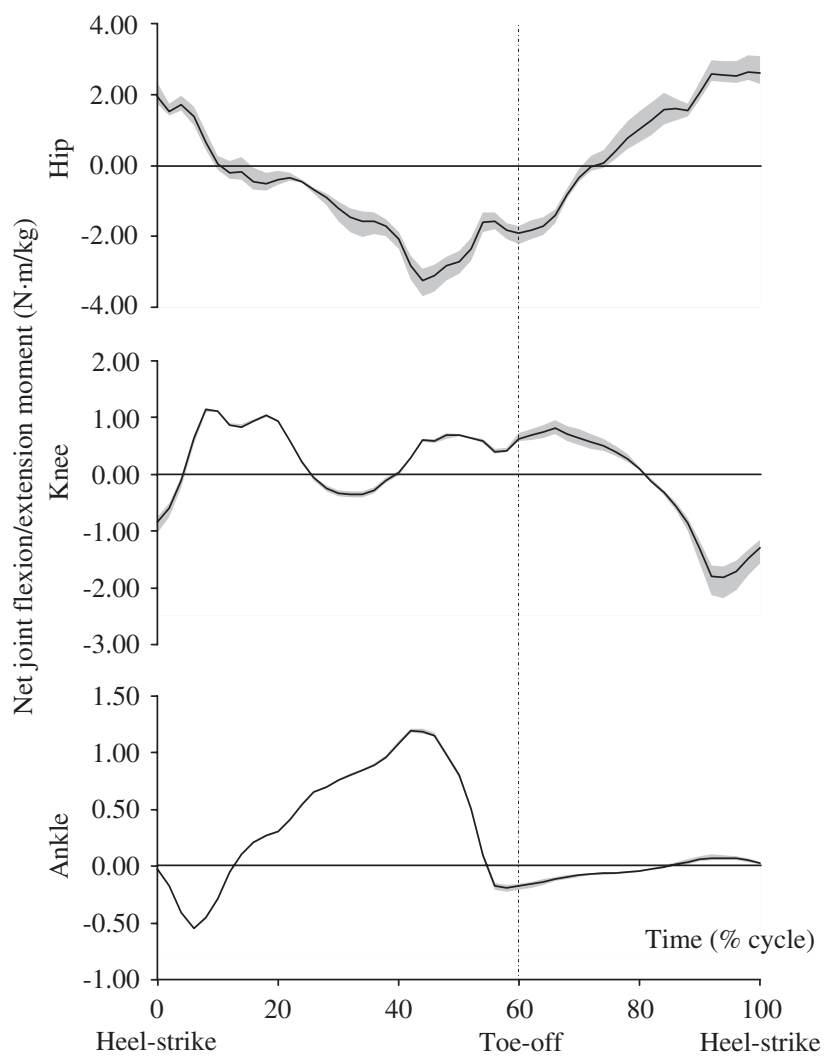

Fig. 2. Black lines represent the mean (over the six selected estimation models) flexion/extension joint moment profiles estimated at the hip, knee and ankle joints for a representative subject during gait at fast cadence. Kinetic values are normalized by subjects' body mass, while time is expressed as percentage of total gait cycle duration. For each graph, the "gray" area represents the range covered by the traces of the kinetics profiles computed using the six selected BSP estimation models.
At the knee joint, no significant Models effect appears, neither on peaks nor on NRMS. Nevertheless, compared to the results at the ankle joint the percentage of variation slightly increases, being maximal for NRMS at preferred cadence during stance $(3.23 \%)$.

At the hip joint, the main Models effect is significant for all NRMS and peaks' values whatever the cadence and the phase of gait, with deviations reaching $17.91 \%$ and $20.11 \%$, respectively. The post hoc comparisons on NRMS and peaks all show that DeLeva outputs significantly differ with those from all other estimation models, and reveal that the outputs derived from cadavers and geometrical estimation models are similar. Interestingly, Z2 outputs at the hip joint are intermediate to those from DeLeva and those from other estimation models, especially Chandler.

Finally, the results show that the influence of varying BSP on joint kinetics is not necessarily most important at fast cadence (see Table 2), with, for example, the mean deviation of NRMS values being larger for low cadence at the hip joint during swing.

\section{Discussion}

The present study was aimed at investigating the sensitivity of joint kinetics estimates to BSP data obtained from different estimation models.

In agreement with Pearsall and Costigan (1999) and Durkin and Dowling (2003), further evidence is provided that BSP estimates are highly sensitive to the BSP estimation model used. More specifically, the estimates

Table 2

Means $( \pm$ SD) of NRMS and peak values observed on flexion/extension moments at the ankle, knee and hip joints in response to BSP variations

\begin{tabular}{|c|c|c|c|c|c|}
\hline \multirow[t]{2}{*}{ Cadence } & \multicolumn{3}{|l|}{ Stance } & \multicolumn{2}{|l|}{ Swing } \\
\hline & Ankle & Knee & Hip & Knee & Hip \\
\hline \multicolumn{6}{|l|}{ NRMS } \\
\hline $\mathrm{L}$ & $\begin{array}{l}0.50 \pm 0.01 \times 10^{-1} \\
0.60\end{array}$ & $\begin{array}{l}0.51 \pm 0.05 \times 10^{-1} \\
2.35\end{array}$ & $\begin{array}{l}0.45 \pm 0.01^{*} \\
7.94\end{array}$ & $\begin{array}{l}0.35 \pm 0.01 \\
10.23\end{array}$ & $\begin{array}{l}0.28 \pm 0.01^{*} \\
14.79\end{array}$ \\
\hline $\mathrm{P}$ & $\begin{array}{l}0.49 \pm 0.01 \times 10^{-1 *} \\
0.61\end{array}$ & $\begin{array}{l}0.43 \pm 0.06 \times 10^{-1} \\
3.23\end{array}$ & $\begin{array}{l}0.40 \pm 0.02^{*} \\
12.64\end{array}$ & $\begin{array}{l}0.34 \pm 0.02 \\
12.80\end{array}$ & $\begin{array}{l}0.29 \pm 0.01 * \\
11.01\end{array}$ \\
\hline $\mathrm{F}$ & $\begin{array}{l}0.50 \pm 0.01 \times 10^{-1 *} \\
0.80\end{array}$ & $\begin{array}{l}0.39 \pm 0.03 \times 10^{-1} \\
1.78\end{array}$ & $\begin{array}{l}0.37 \pm 0.03^{*} \\
17.91\end{array}$ & $\begin{array}{l}0.34 \pm 0.01 \\
11.27\end{array}$ & $\begin{array}{l}0.29 \pm 0.01^{*} \\
10.90\end{array}$ \\
\hline \multicolumn{6}{|c|}{ Peaks (N m/kg) } \\
\hline $\mathrm{L}$ & $\begin{array}{l}1.23 \pm 0.02 \times 10^{-1 *} \\
0.41\end{array}$ & $\begin{array}{l}0.57 \pm 0.03 \times 10^{-1} \\
1.40\end{array}$ & $\begin{array}{l}-1.13 \pm 0.05^{*} \\
11.14\end{array}$ & $\begin{array}{l}-0.40 \pm 0.02 \\
13.53\end{array}$ & $\begin{array}{l}0.62 \pm 0.04^{*} \\
16.63\end{array}$ \\
\hline $\mathrm{P}$ & $\begin{array}{l}1.24 \pm 0.02 \times 10^{-1} \\
0.49\end{array}$ & $\begin{array}{l}0.95 \pm 0.06 \times 10^{-1} \\
1.48\end{array}$ & $\begin{array}{l}-1.91 \pm 0.12^{*} \\
15.43\end{array}$ & $\begin{array}{l}-0.65 \pm 0.03 \\
11.06\end{array}$ & $\begin{array}{l}1.07 \pm 0.07^{*} \\
20.11\end{array}$ \\
\hline F & $\begin{array}{l}1.34 \pm 0.03 \times 10^{-1 *} \\
0.67\end{array}$ & $\begin{array}{l}0.96 \pm 0.05 \times 10^{-1} \\
1.15\end{array}$ & $\begin{array}{l}-2.49 \pm 0.19^{*} \\
19.29\end{array}$ & $\begin{array}{l}-1.07 \pm 0.05 \\
10.90\end{array}$ & $\begin{array}{l}1.86 \pm 0.11^{*} \\
13.36\end{array}$ \\
\hline
\end{tabular}

Values in italic are the percentages of variation of these variables within Models. L, P, F correspond to low, preferred and fast cadence, respectively. Due to low peak-to-peak amplitudes and minor variations of the ankle flexion/extension moment during swing, this variable was not considered for comparisons.

*Indicates significant main Models effects $(p<0.05)$ for corresponding cells. 
of the mass and moment of inertia derived from Hanavan (1964) for both the foot and shank typically highlight that modeling body segments as simple geometric shapes can largely affect BSP values, especially for the segments with complex contours. Also, the large difference observed for the thigh mass values when comparing those from cadaver-based and those from living-based models, emphasizes the importance of segmentation methods (Dempster, 1955; Zatsiorsky and Seluyanov, 1983), considering especially that setting different boundaries for a segment modifies its volume. In addition, the differences in the populations used to formulate the BSP estimation models can explain the discrepancies between BSP values, since the relative amount of bone, muscle and adipose tissue in a body segment depends on the age of subjects (Kyle et al., 2001).

Given the range of variation in BSP values observed in the present study, their influence on the solutions obtained from inverse dynamics should be carefully considered.

The results show that both NRMS and peaks can be largely affected when anthropometric inputs are estimated from different models, supporting the idea that the sensitivity of inverse dynamics solutions to BSP data cannot be neglected (Andrews and Mish, 1996; Kingma et al., 1996; Silva and Ambrosio, 2004). However, particular cases for which the differences in BSP affect a single component show negligible variation in joint kinetics, even when statistically significant. Particularly, between $\mathrm{Z} 2$ and $\mathrm{Z} 1$ at the foot, the variation of $13.62 \%$ in the transverse moment of inertia leads to insignificant variations in both NRMS and peaks. This conclusion agrees with Pearsall and Costigan (1999), and also holds when the variations in BSP estimates are low. On the contrary, maximal discrepancies appear on NRMS and peaks when all the variations of BSP components affect the joint kinetics the same way: the difference within the moments arises from variations in all the individual term of equations of motion. Thus, the increase by $19.45 \%$ of peaks at the hip joint between DeLeva and cadaverbased models results from combining the effects of increases by $23.02 \%$ of masses, $33.81 \%$ of moments of inertia and $10.12 \%$ of center of mass locations. This behavior explains first how the deviations of joint kinetics propagate to the upper joints depending on the cadence, and second, that large differences in BSP can also produce similar joint kinetics.

From a more general viewpoint, statistically similar kinetic estimates are obtained when using BSP data derived from Chandler, Dempster or Hanavan models, but these values differ from those computed with $\mathrm{Z} 1, \mathrm{Z} 2$ and DeLeva. Moreover, Durkin and Dowling (2003) reported that $\mathrm{Z} 2$ provides BSP values closer to in vivo measurements than those from Z1, Hanavan and Dempster models. Therefore, we find that Z2 model could be strongly recommended to assess joint kinetics, especially for gait analysis in young and healthy subjects. This can be of importance to avoid misinterpretation in the action of muscles, because hip joint kinetics at fast cadence reveal that changing BSP values can modify the time instant when the polarity of the moment inverts (Fig. 2): the duration of hip flexor activity could differ by up to $10.00 \%$. Finally, this study clarifies how joint kinetics are sensitive to the interdependence linking the BSP components, but further investigations remain necessary to extend these results to other movements performed under different conditions.

\section{References}

Andrews, J.G., Mish, S.P., 1996. Methods for investigating the sensitivity of joint resultants to body segment parameter variations. Journal of Biomechanics 29, 651-654.

Besier, T.F., Sturnieks, D.L., Alderson, J.A., Lloyd, D.G., 2003. Repeatability of gait data using a functional hip joint centre and a mean helical knee axis. Journal of Biomechanics 36, 1159-1168.

Cahouët, V., Martin, L., Amarantini, D., 2002. Static optimal estimation of joint accelerations for inverse dynamics problem solution. Journal of Biomechanics 35, 1507-1513.

Challis, J.H., Kerwin, D.G., 1996. Quantification of the uncertainties in resultant joint moments computed in a dynamic activity. Journal of Sports Sciences 14, 219-231.

Chandler, R.F., Clauser, C.E., McConville, J.T., Reynolds, H.M., Young, J.W., 1975. Investigation of inertial properties of the human body. AMRL-TR-74-137, Ohio.

Charlton, I.W., Tate, P., Smyth, P., Roren, L., 2004. Repeatability of an optimized lower body model. Gait and Posture 20, 213-221.

De Leva, P., 1996. Adjustments to Zatsiorsky-Seluyanov's segment inertia parameters. Journal of Biomechanics 29, 1223-1230.

Dempster, W.E., 1955. Space requirements of the seated operator. WADC-TR-55-159, Wright Air Development, Ohio.

Durkin, J.L., Dowling, J.J., 2003. Analysis of body segment parameter differences between four human populations and the estimation errors of four popular mathematical models. Journal of Biomechanical Engineering 125, 515-522.

Ganley, K.J., Powers, C.M., 2004. Determination of lower extremity anthropometric parameters using dual energy X-ray absorptiometry: the influence on net joint moments during gait. Clinical Biomechanics 19, 50-56.

Giakas, G., Baltzopoulos, V., 1997. Optimal digital filtering requires a different cut-off frequency strategy for the determination of the higher derivatives. Journal of Biomechanics 30, 851-855.

Hanavan, E.P., 1964. A Mathematical Model of the Human Body. Aerospace Medical Division, Ohio, pp. 64-102.

Hatze, H., 2000. The inverse dynamics problem of neuromuscular control. Biological Cybernetics 82, 133-141.

Holden, J.P., Stanhope, S.J., 1998. The effect of variation in knee center location estimates on net knee joint moments. Gait and Posture 7, 1-6.

Kingma, I., Toussaint, H.M., De Looze, M.P., Van Dieen, J.H., 1996. Segment inertial parameter evaluation in two anthropometric models by application of a dynamic linked segment model. Journal of Biomechanics 29, 693-704.

Kyle, U.G., Genton, L., Hans, D., Karsegard, V.L., Michel, J., Slosman, D.O., Pichard, C., 2001. Total body mass, fat mass, fatfree mass, and skeletal muscle in older people: cross-sectional differences in 60-year-old persons. Journal of the American Geriatrics Society 49, 1633-1640. 
McCaw, S.T., DeVita, P., 1995. Errors in alignment of center of pressure and foot coordinates affect predicted lower extremity torques. Journal of Biomechanics 28, 985-988.

Pearsall, D.J., Costigan, P.A., 1999. The effect of segment parameter error on gait analysis results. Gait and Posture 9, 173-183.

Shan, G., Bohn, C., 2003. Anthropometrical data and coefficients of regression related to gender and race. Applied Ergonomics 34 (4), $327-337$.

Silva, M.P., Ambrosio, J.A., 2004. Sensitivity of the results produced by the inverse dynamic analysis of a human stride to perturbed input data. Gait and Posture 19, 35-49.

Van den Bogert A.J., de Koning, J.J., 1996. On optimal filtering for inverse dynamics analysis. Proceedings of the IXth Biennial Conference of the Canadian Society for Biomechanics, Vancouver, pp. 214-215.

Winter, D., 1990. Biomechanics and Motor Control of Human Movement. Wiley-Interscience, Toronto, Ontario.

Zatsiorsky, V., Seluyanov, V., 1983. The mass and inertial characteristics of main segments of the human body. In: Human Kinetics Matsui, H., Kobayashi, K. (Eds.), Biomechanics VIII-B. Champaign, Illinois, USA, pp. 1152-1159.

Zatsiorsky, V., Seluyanov, V., Chugunova, L., 1990. In vivo body segment inertial parameters determination using a gamma scanner method. In: Berme, N., Cappozzo, A. (Eds.), Biomechanics of Human Movement: Application in Rehabilitation, Sports and Ergonomics. Bertec, Worthington, pp. 86-202.

\section{Further reading}

Cappozzo, A., Leo, T., Pedotti, A., 1975. A general computing method for the analysis of human locomotion. Journal of Biomechanics 8 , $307-320$.
Chao, E.Y., Rim, K., 1973. Application of optimization principles in determining the applied moments in human leg joints during gait. Journal of Biomechanics 6, 497-510.

Chiari, L., Croce, U.D., Leardini, A., Cappozzo, A., 2005. Human movement analysis using stereophotogrammetry: Part 2: instrumental errors. Gait and Posture 21, 197-211.

Croce, U.D., Leardini, A., Chiari, L., Cappozzo, A., 2005. Human movement analysis using stereophotogrammetry: Part 4: assessment of anatomical landmark misplacement and its effects on joint kinematics. Gait and Posture 21, 226-237.

Hatze, H., 2002. The fundamental problem of myoskeletal inverse dynamics and its implication. Journal of Biomechanics 35, $109-115$.

Jones, S.F., Twigg, P.C., Scally, A.J., Buckley, J.G., 2005. The gait initiation process in unilateral lower-limb amputees when stepping up and stepping down to a new level. Clinical Biomechanics 20, 405-413.

Kubo, M., Holt, K.G., Saltzman, E., Wagenaar, R.C. Changes in axial stiffness of the trunk as a function of walking speed. Journal of Biomechanics (in press).

Leardini, A., Cappozzo, A., Catani, F., Toksvig-Larsen, S., Petitto, A., Sforza, V., Cassanelli, G., Giannini, S., 1999. Validation of a functional method for the estimation of hip joint center location. Journal of Biomechanics 32, 99-103.

Leardini, A., Chiari, L., Croce, U.D., Cappozzo, A., 2005. Human movement analysis using stereophotogrammetry: Part 3: soft tissue artifact assessment and compensation. Gait and Posture 21, 212-225. 